but as a matter of fact the great majority of them never published anything in Esperanto. Their support is purely platonic, and as it was given before the birth of Ido, it shows their approval of the general idea of an international language more than of that particular form of such a language. It is a significant fact that not a single philologist has accepted Esperanto in its Zamenhofian shape; the only one mentioned in Esperanto papers is Baudouin de Courtenay in St. Petersburg, but he has publicly declared that "Of course, Esperanto needs improvements," and though he does not accept Ido in every detail, he says that it is better than Esperanto in many respects. But the leading French Esperanto paper (Lingvo Internacia) refused to print a protest from Baudouin de Courtenay after they had printed what purported to be an article by him entirely in favor of Esperanto, which he had never written.

I am optimist enough to believe that the present tactics of many Esperantists will soon cease, and that they will then see that a good cause can only be furthered by a loyal discussion of the pros and cons without regard to persons. No great invention, no great scientific discovery, ever sprang into the world fullfledged; they all have required the patient cooperation of many minds. Yet we are to believe that Dr. Zamenhof's invention of 1887 stands in no need of improvement in its vital elements; and it is considered a sacrilege to whisper that its alphabet is cumbersome, many of its roots badly selected, much of its grammar too capricious and its methods of wordformation insufficient and amateurish, and that by setting to work on scientific principles it is possible to devise a much better language of a much more truly international character, " not perfect," perhaps, " but always perfectible."

Columbia University

\section{OtTo JesPeRsen}

\section{SCIENTISTS AND ESPERANTO}

IN ScIence for December 3 appears an interesting note on Esperanto from the pen of Professor Tingle, in which he criticizes the statement made in a former article of my own, that the adoption of an international language is the solution of many difficulties for scientific men. Waiving the fact that he applies the quotation he makes in a manner other than the context will strictly warrant, his remarks still leave unshaken my conviction that the use of the international language would be a means of lightening the linguistic burdens of all scientific workers, and among them, of the chemists; even under the somewhat drastic conditions of the hypothetical case he cites.

I venture to believe, that if, as he supposes, subsequent to January 1, 1910, all chemical communications were compelled to be made in Esperanto, the result would not be, as he fears, simply the additional burden of another language to be learned, but that, on the contrary, chemists would discover that they did not need to be also expert linguists in order to keep in touch with the movements of their science throughout the world, and that, while possibly a reading knowledge of certain modern national tongues, for perusal of matter already chronicled, was still desirable, a speaking and writing knowledge, a very different matter, had become, almost, if not entirely, unnecessary in their scientific work. Such an intimate knowledge would be needed of one language only and that, the simplest of all, Esperanto. The authors of the communications would also find a much larger audience, to the advantage both of themselves and of the world in general.

It is true that sometimes, in quoting from existing writings, it is desirable to use the language in which the author wrote, in order to clearly express his thought, and to this extent would it be necessary to permit the use of other tongues than the international one, but this would be a very small item compared with the immense gain that all the new facts and theories of the science would be expressed in the world language, and, as the years rolled by, the necessity of using any national language in such international communications and contributions would grow less and less-to finally disappear. 
Even the reading knowledge of natural tongues required for study or reference would be immediately reduced to a minimum, because large amounts of matter which at present are not translated into the national languages, for no other reason than that the demand for it in each tongue will not justify the expense, could be translated into the accepted international idiom, as it would then have the world for a market. Every year this minimum would steadily approach zero, as new theories and methods superseded old and were given to the world by their authors, in Esperanto.

The desirability of having an author's own words and expressions, whether one is studying him privately or quoting from his works, is only another reason why that author, when desiring to reach all the world, should write in a common tongue, which all the world can easily understand, and the acquisition of which, to those chemists or other scientists of the present day who already know English, French and German, is but child's play. Such should be willing to accept this "burden" (?), in order that their less gifted brethren may have also the advantages of reading in the original, scientific matter to be hereafter recorded.

We can not change the writings of the past, but the book of the future is ours to make or mar, and how better can we fill its pages than by recording the new triumphs of science in one language, an international language, which even her humblest worshipper may readily acquire? J. D. HAILMAN

\section{Pittisburgh,}

December 13, 1909

\section{RELATIVITY AND SOME OF ITS CONSEQUENCES}

The discussion of relativity in the recent meeting of the American Physical Society in Boston was a serious disappointment to me. It interfered with some of my future plans, and it left me in the dark concerning how those plans might be amended.

I had intended, when I became a disembodied spirit, to start outwards from my space locus at that instant, and to travel with twice the velocity of light along my individual time emanations, until I had reached the beginning of my time career. I was, and am, curious to see how that history would appear when reviewed backwards in this manner. I had then planned to pause until my history should overtake me again. This would give me a chance to see myself as others had seen me. I had previously realized that this would be a cruise which would require a great deal of skill by reason of the constantly changing position of my individual time and space locus, due to terrestrial and solar motion. Still I had thought it possible to follow the tangled trail, by keeping my course at right angles to the daily and annual wave fronts, as they successively presented themselves.

It had seemed possible also to gain in this manner the experimental data necessary in the framing of a general system of vector analysis. This system would enable one to start with the space locus at which the earthly clay was shaken off, and to locate with reference to it any other point in his own time and space career. An increase in the length of the space vector in any direction would simultaneously carry one outward in space, forward in time and backward in history.

The Boston discussion did not supply one item of information which I had confidently expected. It is necessary that one should, on such a cruise, know the precise number of cubic miles in a cubic year. This information was not given us. In addition it was revealed that it is not possible for any velocity to be greater than that of light, or $3 \times 10^{10} \mathrm{~cm}$. per second.

Is this conclusion final? We can see that the waves which contain our spoken words lag greatly on those which embody our visible acts. May there not be some more refined medium, a spiritual medium, perhaps, in which $v$ can exceed $3 \times 10^{10} \mathrm{~cm}$. per second?

Evidently we must no longer sneeze at discussions concerning the relation between the whereness of the when and the whenness of the where. The equations placed on that 